\title{
SELEÇÃO DE PROGÊNIES DE COFFEA ARABICA COM RESISTÊNCIA SIMULTÂNEA À MANCHA AUREOLADA E À FERRUGEM ALARANJADA ${ }^{(1)}$
}

\author{
MARCOS RAFAEL PETEK ${ }^{(2,4)}$; TUMORU SERA ${ }^{(2)}$; GUSTAVO HIROSHI SERA ${ }^{(2)}$; \\ INÊS CRISTINA DE BATISTA FONSECA ${ }^{(3)}$; DHALTON SHIGUER ITO ${ }^{(2)}$
}

\begin{abstract}
RESUMO
O objetivo desta investigação foi estudar progênies de Coffea arabica quanto a resistência à ferrugem alaranjada, causada por Hemileia vastatrix, e à mancha aureolada, causada por Pseudomonas syringae pv. garcae. O experimento foi instalado no Centro de Produção e Experimentação de Londrina, do Instituto Agronômico do Paraná. Utilizou-se delineamento em blocos ao acaso, com três repetições, 13 tratamentos (11 progênies e as testemunhas 'IAPAR 59' e 'Catuaí Vermelho IAC 81'). Os resultados sugerem investigar a possibilidade da ocorrência de novo(s) patotipo(s) de P. syringae pv. garcae no Paraná. Observou-se na cultivar 'IAPAR 59' resistência suficiente para reduzir danos provocados por P. syringae pv. garcae, causador da mancha aureolada, em regiões de alta ocorrência do patógeno no Paraná. Na progênie "Catuaí" x "Icatú" PRFB 2-27-1/F5 (IAPAR 96095) verificou-se resistência simultânea à ferrugem alaranjada e à mancha aureolada e deverá ser testada em ensaios regionais.
\end{abstract}

Palavras-chave: melhoramento de café, resistência à doenças, cultivar, cafeicultura.

\section{ABSTRACT \\ SELECTION OF PROGENIES OF COFFEA ARABICA WITH SIMULTANEOUS RESISTANCE TO BACTERIAL BLIGHT AND LEAF RUST}

This research aimed at to study $C$. arabica progenies as to resistances to bacterial blight "mancha aureolada", caused by Pseudomonas syringae pv. garcae, and coffee leaf rust, caused by Hemileia vastatrix. The experiment was carried out in the Centro de Produção e Experimentação de Londrina, Instituto Agronômico do Paraná. It was set in a randomized complete block design with 13 treatments (11 progenies and the controls 'IAPAR 59' and 'Catuaí Vermelho IAC 81') and three replications. The results suggest the ocurrence of new(s) pathotype(s) of P. syringae pv. garcae in Paraná State. The IAPAR 59 cultivar is an option to minimize the damage caused by P. syringae pv. garcae in areas of high incidence of this pathogen. The progeny PRFB 2-27-1/F5 (IAPAR 96095) from "Catuaí" x "Icatú" cross presented simultaneous resistance to leaf rust and to bacterial blight ("mancha aureolada"). It will be tested in future regional trials.

Key words: coffee breeding, disease resistance, cultivar, Pseudomonas syringae pv. garcae, Hemileia vastatrix.

( $\left.{ }^{1}\right)$ Recebido para publicação em 2 de fevereiro de 2005 e aceito em 23 de janeiro de 2006.

$\left(^{2}\right)$ Área de Genética e Melhoramento de Café, Instituto Agronômico do Paraná, Rodovia Celso Garcia Cid, km 375, Caixa Postal 481, 86047-902 Londrina (PR). E-mail: mrpetek@iac.sp.gov.br ; tsera@iapar.br

$\left({ }^{3}\right)$ Centro de Ciências Agrárias, Departamento de Agronomia, Universidade Estadual de Londrina. Rodovia Celso Garcia Cid (PR 445), km 380, Caixa Postal 6001, 86051-990 Londrina (PR), Brasil. E-mail: inescbf@uel.br.

$\left({ }^{4}\right)$ Bolsista da CAPES. 


\section{INTRODUÇÃO}

A cafeicultura brasileira tem passado por diversas modificações na busca de um sistema de cultivo mais auto-sustentável. Importantes avanços foram alcançados, como o sistema de plantio adensado e o cultivo orgânico, que visam principalmente aumentar a rentabilidade do cafeicultor e diminuir a contaminação do meio ambiente. $\mathrm{O}$ uso de cultivares resistentes a doenças e pragas, adaptadas a cada sistema de cultivo regional, é a tecnologia mais eficiente e de menor custo para o desenvolvimento da auto-sustentabilidade, que proporciona maior rentabilidade e retorno social além da diminuição no uso de agrotóxicos.

As principais doenças que afetam a cafeicultura brasileira são a ferrugem alaranjada, causada por Hemileia vastatrix (VARZEA et al., 2002); a mancha aureolada, causada por Pseudomonas syringae pv. garcae (SERA, 2001; SERA et al., 2002); a cercosporiose, causada por Cercospora coffeicola (SERA, 2001; Sera et al., 2002) e, mais recentemente, a antracnose, causada por Colletotrichum spp. (PARADELA FiLHO et al., 2001).

No mundo, a ferrugem alaranjada é a principal doença em abrangência e danos. Já existem várias cultivares brasileiras resistentes como IAPAR 59, TUPI IAC 1669-33, Obatã IAC 1669-20, OEIRAS MG6851, Paraíso, Catucaí e outras. Os mecanismos e fatores de resistência são bem estudados, apesar disso, é recomendável um contínuo trabalho de melhoramento de cultivares resistentes a $H$. vastatrix, com maior número de genes qualitativos e quantitativos (VARZEA et al., 2002). O contínuo aparecimento de novas raças fisiológicas desse patógeno tem ocasionado a quebra de resistência em algumas cultivares antes consideradas resistentes e a durabilidade da resistência das cultivares atuais é difícil de ser prevista (VARZEA et al., 2002).

A mancha aureolada não tem a mesma importância econômica da ferrugem alaranjada, mas tem-se tornado limitante em regiões mais frias, em face exposta ao vento (SERA, 2000), no Paraná, em São Paulo e no Sul de Minas Gerais, principalmente em lavouras novas, podadas e em viveiros (MOHAN, 1976).

MoraEs et al. (1974) identificaram que o fator genético Sh1, em C. arabica, observado nos cafés Harar, Dilla e Alghe, S12 Kaffa e Geisha, originados da Etiópia, confere resistência específica a determinadas raças de $H$. vastatrix, e também à bactéria P. syringae pv. garcae. MoHAN et al. (1978) verificaram imunidade na variedade Geisha.
As cultivares Mundo Novo, Catuaí e Bourbom são consideradas suscetíveis (MORAES et al., 1974; Mohan et al., 1978; CARdoso e Sera, 1983).

Mohan et al. (1978) e CARdoso e Sera (1983) observaram variabilidade genética para resistência à mancha aureolada entre progênies derivadas do cruzamento "Caturra" x "Híbrido de Timor" e entre progênies resistentes à ferrugem alaranjada, concluindo que existem outros fatores além do gene Sh1 (Moraes et al., 1974), que também conferem resistência à mancha aureolada. Dentro do gemoplasma Icatu, os autores identificaram progênies resistentes e suscetíveis, porém nenhuma imune ou altamente resistente, indicando a presença de resistência quantitativa.

Petek et al. (2001), estudando progênies derivadas do cruzamento 'IAPAR-59' x (C. arabica Sh1 x Catuaí Vermelho IAC-81), demonstraram que além do gene Sh1, existem um ou mais genes que também conferem resistência a $P$. syringae pv. garcae.

Portanto, observa-se, em trabalhos anteriores, que além do fator Sh1, identificado por proporcionar resistência qualitativa à mancha aureolada (MORAES et al., 1974), há evidências de que existem outros genes que propiciam resistência quantitativa e qualitativa ao patógeno, provavelmente oriundos de $C$. canephora ("Icatu" e "Híbrido de Timor") (Moraes et al., 1974; Mohan et al., 1978; Cardoso e Sera, 1983; Petek et al., 2001). Existe, portanto, variabilidade genética para obtenção de cultivares com resistência simultânea a $P$. syringae pv. garcae e a $H$. vastatrix.

O objetivo deste estudo foi identificar e selecionar progênies de $C$. arabica com resistência simultânea à ferrugem alaranjada e à mancha aureolada.

\section{MATERIAL E MÉTODOS}

O experimento foi instalado em solo do tipo Latossolo Vermelho distrófico, no Centro de Produção e Experimentação de Londrina do Instituto Agronômico do Paraná, com temperatura média anual de $20,8^{\circ} \mathrm{C}$, a 585 metros de altitude, latitude $23^{\circ} 22^{\prime} \mathrm{S}$ e longitude $51^{\circ} 10^{\prime} \mathrm{W}$ em maio de 1997 . Utilizou-se delineamento em blocos ao acaso, com três repetições, 13 tratamentos (11 progênies e as testemunhas 'IAPAR 59' e 'Catuaí Vermelho IAC 81', respectivamente, resistente e suscetível à ferrugem alaranjada) e 10 plantas/parcela plantadas em espaçamento $2,5 \times 0,5$ metros. Devido à ocorrência de severa geada em 2000 (as plantas desse experimento foram recepadas), algumas morreram, permanecendo de sete a dez plantas/parcela. Os tratamentos estão descritos na tabela 1 . 
Tabela 1. Descrição das progênies de Coffea arabica

\begin{tabular}{|c|c|}
\hline Descrição Tratamento & \\
\hline 'IAPAR 59' & 1 (I59) \\
\hline 'Catuaí Vermelho IAC 81' & $2\left(\mathrm{C}_{1}^{1} 81\right)$ \\
\hline "Catuaí" x "Icatú" PRFB 2-5-1 \ $\mathrm{F}_{5}$ & 3 (CíxIc) \\
\hline 'Vila Sarchi' x "Híbrido de Timor" PRFB 1-13-3 \ $F_{5}$ & $4(\mathrm{VsxHT})$ \\
\hline ‘Caturra' x “Catuaí 2,3” PRFB 1-14-3 \ $\mathrm{F}_{5}$ & $5\left(\mathrm{CtxC}{ }_{2,3}\right)$ \\
\hline 'Caturra' x "Híbrido de Timor" PRFB 2-7-1 \ $\mathrm{F}_{5}$ & $6(\mathrm{CtxHT})$ \\
\hline “Catuaí" x “Icatú" PRFB 2-27-1 \ $F_{5}$ & 7 (CíxIc) \\
\hline “Caturra' x "Híbrido de Timor" PRF II 2-17-1 \ $\mathrm{F}_{5}$ & $8(\mathrm{CtxHT})$ \\
\hline 'Caturra' x "Híbrido de Timor" PRF II 2-17-3 \ $\mathrm{F}_{5}$ & $9(\mathrm{CtxHT})$ \\
\hline 'Caturra' x "Híbrido de Timor" PRF III 2-9-2 \ $F_{5}$ & $10(\mathrm{CtxHT})$ \\
\hline ‘Caturra' x “Híbrido de Timor” PRF III 2-14-2 \ F & $11(\mathrm{CtxHT})$ \\
\hline “Etiópia Sh1” x ‘Catuaí IAC 81’ HRFB 3-21-1 \ F & 12 (EtxCí) \\
\hline “Etiópia Sh1” x ‘Catuaí IAC 81’ HRFB 1-21-3 \ $\mathrm{F}_{3}$ & 13 (EtxCí) \\
\hline
\end{tabular}

\subsection{Caracteres avaliados}

Para todos os caracteres, exceto resistência à mancha aureolada e porte, as datas das avaliações foram: 25/5/2000; 15/8/2002; 28/5/2003; 8/7/ 2004. As análises foram feitas com as médias dos quatro anos.

A reação à mancha aureolada (MA) foi avaliada com infestação natural em campo, segundo uma escala de notas, adaptado de MoHan et al. (1978), sendo: 1 = resistente (sem a presença de lesões na planta), 2 = moderada resistência (poucas e pequenas lesões nas folhas, sem a presença de halo amarelo), 3 $=$ moderada suscetibilidade (poucas lesões nas folhas, com halo amarelo), e $4=$ suscetível (muitas lesões nas folhas, com halo amarelo e necrose terminal de ramos). A avaliação foi realizada em 11 de setembro de 2001, um ano após a recepa das plantas.

A reação à ferrugem $(\mathrm{F})$ foi avaliada com infestação natural em campo, segundo uma escala de notas variando de 1 a 5, sendo: 1 = ausência de pústulas (alta resistência), 2 = poucas folhas com pústulas e sem esporos (resistência), 3 = poucas pústulas por folha com grande produção de esporos e pouco distribuídas (moderadamente suscetível), $4=$ média quantidade de pústulas por folha, distribuídas na planta, com grande produção de esporos (suscetibilidade) e $5=$ alta quantidade de pústulas, com grande produção de esporos e desfolha intensa da planta (alta suscetibilidade). Nenhum tratamento fitossanitário foi aplicado as plantas.

$\mathrm{O}$ vigor vegetativo $(\mathrm{V})$ de cada planta do experimento foi avaliado pelo índice de avaliação visual (FAZUOLI, 1991), segundo uma escala de 1 a 10, sendo: 1 = planta amarela com abundante seca de ramos e 10 = planta verde-escura com abundante ramificação e elevada carga pendente.

O potencial de produção $(\mathrm{P})$ de cada planta foi avaliado visualmente em litros de fruto cereja/ planta, levando em consideração o tamanho dos grãos, número de frutos/roseta e quantidade de rosetas frutificadas.

A produção em litros de fruto cereja/planta (litros/planta) foi transformada para produtividade/ ha $(\mathrm{P})$, com base em número de plantas/hectare (pl/ ha) diferentes de acordo com o porte, segundo a expressão: $\mathrm{P}=$ (litros / planta $\times$ pl/ha)/500 (500 é um valor médio em litros de café da roça para obter uma saca de café beneficiado). O porte foi avaliado em cada planta, sendo: 1 = "Villa Lobos" (anão); 2 = 'Iapar 59' (pequeno); 3 = 'Catuaí Vermelho IAC 81' (médio); 4 = 'Mundo Novo' (grande); 5 = "Maragogipe" (muito grande, com internós maiores). Foram estabelecidos quatro espaçamentos diferentes, sendo: porte $1=2,0$ x 0,5 metros $(10.000 \mathrm{pl} / \mathrm{ha})$, porte $2=2,5 \times 0,5$ metros $(8.000 \mathrm{pl} / \mathrm{ha})$, porte $3=3,0 \times 0,6$ metros $(5.556 \mathrm{pl} / \mathrm{ha}) \mathrm{e}$ porte $4=3,5 \times 0,7(4.081 \mathrm{pl} / \mathrm{ha})$.

O tamanho dos grãos (TG) foi avaliado, atribuindo-lhes notas de 1 a 5 . Foram utilizadas cultivares comerciais de tamanho de grãos conhecidos como padrão, em que: 1 = (miúda) semelhante a 'Mokka', 2 = (pequena) semelhante a 'Icatú Precoce IAC 3282', 3 = (média) semelhante a 'Catuaí Vermelho IAC 81 ', 4 = (grande) semelhante a 'Acaiá IAC 474-7' e $5=$ (gigante) semelhante a 'Maragogipe'. 
Cada planta foi classificada quanto à época de maturação dos frutos (M) em: supertardia, tardia ('Catuaí Vermelho IAC 81'), semiprecoce ('IAPAR 59'), precoce e superprecoce, atribuindo-lhes respectivamente as notas 1, 2, 3, 4 e 5. As notas puderam variar conforme a época em que essa característica foi avaliada.

\subsection{Critérios para seleção entre e dentro de progênie}

A seleção entre e dentro de progênies foi baseada, primeiramente, na resistência simultânea à mancha aureolada e à ferrugem alaranjada, como critério eliminatório. Posteriormente, foram analisados o vigor vegetativo e o potencial de produção, que foram, também, critérios de eliminação, se abaixo da média ou muito abaixo das testemunhas. O tamanho dos grãos foi o critério seguinte, sendo eliminados aqueles miúdos (semelhantes a "Mokka") ou menor que 'Icatu Precoce IAC 3282'. A época de maturação dos frutos não foi critério para eliminação, porém deve ser considerado conforme as regiões de cultivo possíveis.

\subsection{Análises genético-estatísticas}

Realizaram-se análises de variância ao nível de médias de tratamentos para todos os caracteres e teste de Scott-Knott $(\mathrm{P} ? 0,05)$, para comparações entre médias de todas as características avaliadas. Com base nas análises de variância, foram estimados com o programa estatístico GENES (Cruz, 2001), os seguintes componentes de variância, considerando o efeito de progênies como fixo: variância genética entre

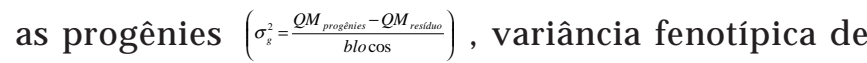

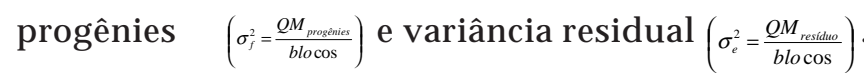
Foram obtidos, também, os coeficientes de determinação genotípicos em nível de média de progênies $\left(b_{m}^{2}=\frac{\sigma_{s}^{2}}{\sigma_{f}^{2}}\right)$.

O ganho genético esperado entre as progênies (GSe), para todas as características, com a seleção, foi estimado por meio da expressão:

$G S_{e}=b^{2} \times D S$, em que: $\mathrm{b}^{2}$ é o coeficiente de determinação genotípico máximo entre as progênies e DS, o diferencial de seleção, estimado por;

DS = MO (Média original do ensaio) - MS (Média da(s) progênie(s) selecionada(s)).

Os ganhos genéticos esperados, com a seleção dentro das progênies (GSd), foram estimados através da expressão:
$G S_{d}=b_{i}^{2} \times D S$, em que: $b^{2}$ é o coeficiente de determinação genotípico do tratamento i, que é estimado por;

$$
b_{i}^{2}=\frac{\left(\sigma_{i}^{2}-\sigma_{t}^{2}\right)}{\sigma_{i}^{2}} \text { em que: } \sigma_{i}^{2} \text { é a variância do }
$$

tratamento i, e $\sigma_{t}^{2}$ é a variância da testemunha.

DSi é o diferencial de seleção no tratamento i, estimado por:

DSi $=$ Mi - Ms, em que: $\mathrm{Mi}=$ média do tratamento i, e Ms = média das plantas selecionadas do tratamento i.

A média melhorada (MM) esperada para a próxima geração é expressa por:

$\mathrm{MM}=\mathrm{MO}$ (média original do ensaio) + GSe +

\section{GSd}

\section{RESULTADOS E DISCUSSÃO}

Verificou-se pela análise de variância (Tabela 2) diferença significativa para todos os caracteres avaliados, a $1 \%$ de probabilidade pelo teste $\mathrm{F}$, exceto para potencial de produção $(P)$, em que não houve diferença significativa. $\mathrm{O}$ coeficiente de variação experimental (Cve (\%)) variou de 3,15 para tamanho dos grãos (TG) a 21,96 para reação à mancha aureolada (MA), revelando boa precisão experimental (Tabela 2).

O potencial de produção apresentou coeficiente de determinação genotípico máximo de 0,438 (Tabela 3). Considerado médio, é um valor que não precisa ser desconsiderado. Os coeficientes de determinação genotípicos máximos, das demais características, foram valores elevados (Tabela 3), que variaram de 0,801 , para vigor vegetativo, a 0,968 para resistência à ferrugem. Portanto, existe variabilidade genética entre progênies, com possibilidades de ganhos genéticos com a seleção.

O teste de comparação entre médias (Tabela 4) para reação à mancha aureolada (MA) separou as progênies em dois grupos. O primeiro, com progênies mais resistentes, incluindo a 'IAPAR 59' (I59), é composto pelos tratamentos 7 (CíxIc), 3 (CíxIc), 13 (EtxCí), 4 (VsxHT), 12 (EtxCí), 9 (CtxHT) e 8 (CtxHT). O grupo das progênies suscetíveis, incluindo a 'Catuaí Vermelho IAC 81' 2 (Cí81), é formado pelos tratamentos 6 (CtxHT), 10 (CtxHT), 5 (CtxCí 2,3) e 11 (CtxHT). Pelo fato dessas progênies terem sido selecionadas anteriormente no campo para resistência, esperava-se que houvesse grau de resistência de moderada a melhor em todas as progênies, porém isso não foi observado. Uma possibilidade é que pode estar ocorrendo novo(s) 
patotipo(s) desse patógeno (PETEK et al., 2002; KAIRU, 1997). Alternativamente, a seleção anteriormente realizada em condições de campo, pode não ter ocorrido com a eficiência esperada.

Pela análise da tabela 5, verifica-se superior resistência à mancha aureolada nos tratamentos 7 (CíxIc), 3 (CíxIc), 1 (I59) (testemunha) e 13 (EtxCí) com $60,00 \%$ a $76,92 \%$ de plantas resistentes. Se considerar a proporção de plantas moderadamente resistentes e resistentes, essas progênies têm de $66,70 \%$ a 90,00\% de plantas nessas categorias. Nas demais progênies verificaram-se entre $37,02 \%$ e $82,75 \%$ de plantas moderadamente suscetíveis a suscetíveis e a testemunha 2 (Cí81), 95,65\%. Esse não foi em média o tratamento mais suscetível, com a maioria das plantas moderadamente suscetíveis. Portanto, esses dados confirmam que 'Catuaí Vermelho IAC 81' é moderadamente suscetível a suscetível, dados que concordam com MoHAN et al. (1978) e indicam as progênies 7 (CíxIc) e 3 (CíxIc) como as mais resistentes à mancha aureolada neste experimento. Mostram também que 'IAPAR 59' possui boa resistência, podendo ser importante opção para diminuir os danos com essa doença em áreas e regiões propícias ao ataque do patógeno.

Para resistência à ferrugem, o teste de médias (Tabela 4) indicou os tratamentos 7 (CíxIc), 10 (CtxHT) e 11 (CtxHT) como resistentes, pois não diferiram significativamente da testemunha resistente 'IAPAR 59' (I59).

Os tratamentos 3 (CíxIc), 12 (EtxCí), 9 (CtxHT), 8 (CtxHT), 6 (CtxHT) e 5 (CtxCí 2,3) não diferiram entre si e foram menos resistentes que a 'IAPAR 59' (Tabela 4), apesar de se observar grande quantidade de plantas resistentes. Outro grupo identificado pelo teste de médias é formado pelos tratamentos 13 (EtxCí) e 4 (VsxHT) que podem ser considerados suscetíveis, apesar de diferirem da testemunha suscetível 'Catuaí Vermelho IAC 81' (Cí81). No mesmo nível de resistência da 'IAPAR 59' estão duas progênies de "Catimor" e uma de "Catucaí", resultados relevantes para o melhoramento de café, buscando identificar materiais com maior diversidade genética para resistência à ferrugem, visando suplantar quebras de resistência de cultivares comerciais até então resistentes (VARZEA et al., 2002).

Tabela 2. Resumo das análises de variância para todas as características avaliadas

\begin{tabular}{lccccccc}
\hline \multirow{2}{*}{ Fontes de Variação } & GL & \multicolumn{5}{c}{ Quadrados médios } \\
\cline { 3 - 7 } & & MA & F & V & P & TG \\
\hline Blocos & 2 & 1,688 & 0,041 & 0,265 & 22,625 & 0,003 & 0,024 \\
Tratamentos & 12 & $1,674^{* *}$ & $2,149^{* *}$ & $0,414^{* *}$ & $47,107^{\text {ns }}$ & $0,061^{* *}$ & $0,432^{* *}$ \\
Resíduo & 24 & 0,274 & 0,068 & 0,082 & 26,478 & 0,009 & 0,016 \\
\hline Média & & 2,39 & 2,17 & 6,79 & 34,65 & 3,10 & 3,66 \\
CVe(\%) & & 21,96 & 12,01 & 4,23 & 14,84 & 3,15 & 3,51 \\
\hline
\end{tabular}

ns: não significativo

*; ** Significativo a $5 \%$ e a $1 \%$ de probabilidade pelo teste $\mathrm{F}$ respectivamente.

MA: reação à mancha aureolada. F: reação à ferrugem. V: vigor vegetativo. P: potencial de produção em sacas beneficiadas/ha. TG: tamanho dos grãos. M: época de maturação dos frutos.

Tabela 3. Parâmetros genéticos estimados entre as progênies do experimento

\begin{tabular}{lcccccc}
\hline \multirow{2}{*}{ Parâmetros } & \multicolumn{5}{c}{ Características avaliadas } \\
\cline { 2 - 6 } & MA & F & V & P & TG \\
\hline$\sigma_{f}^{2}$ & 0,558 & 0,716 & 0,138 & 15,702 & 0,020 & 0,144 \\
$\sigma_{g}^{2}$ & 0,466 & 0,694 & 0,111 & 6,887 & 0,017 & 0,138 \\
$b^{2}$ & 0,836 & 0,968 & 0,801 & 0,438 & 0,843 \\
\hline
\end{tabular}

MA: reação à mancha aureolada; F: reação à ferrugem; V: vigor vegetativo; P: potencial de produção em sacas beneficiadas $\backslash$ ha. TG : tamanho dos grãos. M: época de maturação dos frutos.

$\sigma_{f}^{2}=$ variância fenotípica; $\sigma_{g}^{2}=$ variância genotípica; $b^{2}=$ coeficiente de determinação genotípico. 
Tabela 4. Comparação entre as médias de todas as características avaliadas

\begin{tabular}{|c|c|c|c|c|c|c|c|c|c|}
\hline \multirow{3}{*}{$\begin{array}{l}\text { Tratamentos } \\
7 \text { (CíxIc) }\end{array}$} & \multicolumn{9}{|c|}{ Características $^{1}$} \\
\hline & \multicolumn{2}{|c|}{ MA } & \multicolumn{2}{|c|}{$\mathrm{F}$} & \multirow{2}{*}{$\frac{\mathrm{V}}{7,56 \quad \mathrm{a}}$} & \multirow{2}{*}{$\begin{array}{c}\mathrm{P} \\
37,79 \text { a }\end{array}$} & \multirow{2}{*}{$\frac{\text { TG }}{3,07 \quad b}$} & \multicolumn{2}{|l|}{$\mathrm{M}$} \\
\hline & 1,42 & $\mathrm{a}$ & 1,21 & a & & & & 2,96 & $\mathrm{f}$ \\
\hline 3 (CíxIc) & 1,44 & $\mathrm{a}$ & 2,06 & $b$ & 7,48 a & 36,20 a & $3,10 \mathrm{~b}$ & 3,23 & e \\
\hline 1 (I59) & 1,47 & a & 1,38 & a & $6,95 \mathrm{~b}$ & 40,87 a & 3,20 a & 3,66 & c \\
\hline 13 (EtxCí) & 1,73 & a & 2,91 & c & $6,40 \mathrm{~b}$ & 34,15 a & $3,10 \mathrm{~b}$ & 3,85 & $b$ \\
\hline $4(\mathrm{VsxHT})$ & 2,04 & $\mathrm{a}$ & 3,12 & c & $6,85 \mathrm{~b}$ & 34,14 a & 3,25 a & 3,35 & d \\
\hline 12 (EtxCí) & 2,13 & $\mathrm{a}$ & 2,08 & $b$ & $6,61 \mathrm{~b}$ & 26,26 a & $2,80 \quad \mathrm{c}$ & 4,18 & a \\
\hline $9(\mathrm{CtxHT})$ & 2,38 & $\mathrm{a}$ & 2,22 & $\mathrm{~b}$ & $6,77 \mathrm{~b}$ & 35,54 a & 3,33 a & 3,95 & $b$ \\
\hline $8(\mathrm{CtxHT})$ & 2,40 & $\mathrm{a}$ & 1,95 & $\mathrm{~b}$ & $6,49 \mathrm{~b}$ & 30,68 a & $3,02 \mathrm{~b}$ & 4,22 & a \\
\hline $6 \quad(\mathrm{CtxHT})$ & 3,02 & $\mathrm{~b}$ & 1,80 & $b$ & $6,61 \mathrm{~b}$ & 33,10 a & $3,11 b$ & 4,04 & $b$ \\
\hline $10(\mathrm{CtxHT})$ & 3,05 & $\mathrm{~b}$ & 1,39 & a & $6,67 \mathrm{~b}$ & 40,18 a & $3,04 \mathrm{~b}$ & 3,44 & d \\
\hline $5\left(\mathrm{CtxC}{ }_{12,3}\right)$ & 3,20 & $b$ & 2,20 & $b$ & $6,30 \mathrm{~b}$ & 33,72 a & 3,28 a & 3,68 & c \\
\hline 2 (Cí81) & 3,36 & $\mathrm{~b}$ & 4,28 & d & $6,81 \mathrm{~b}$ & 31,17 a & $2,98 \mathrm{~b}$ & 3,43 & d \\
\hline $11(\mathrm{CtxHT})$ & 3,37 & $b$ & 1,58 & a & $6,75 \mathrm{~b}$ & 36,68 a & $3,01 \mathrm{~b}$ & 3,55 & c \\
\hline
\end{tabular}

MA: reação à mancha aureolada. F: reação à ferrugem. V: vigor vegetativo. P: (Potencial de produção). TG: tamanho dos grãos. M: época de maturação dos frutos. Médias seguidas da mesma letra não diferem entre si pelo teste Scott-Knott $(\mathrm{P}=0,05)$.

Tabela 5. Proporção de plantas resistentes, moderadamente resistentes, moderadamente suscetíveis e suscetíveis à mancha aureolada, em cada tratamento

\begin{tabular}{|c|c|c|c|c|c|c|c|c|c|c|}
\hline \multirow[t]{2}{*}{ Tratamento } & \multicolumn{2}{|c|}{ Resistente } & \multicolumn{2}{|c|}{$\begin{array}{l}\text { Moderadamente } \\
\text { Resistente }\end{array}$} & \multicolumn{2}{|c|}{$\begin{array}{c}\text { Moderadamente } \\
\text { Suscetível }\end{array}$} & \multicolumn{2}{|c|}{ Suscetível } & \multicolumn{2}{|c|}{ Total } \\
\hline & $\mathrm{P}^{1}$ & $\%$ & $\mathrm{P}^{1}$ & $\%$ & $\mathrm{P}^{1}$ & $\%$ & $\mathrm{P}^{1}$ & $\%$ & $\mathrm{P}^{1}$ & $\%$ \\
\hline 7 (CíxIc) & 20 & 76,92 & 2 & 7,69 & 2 & 7,69 & 2 & 7,69 & 26 & 100 \\
\hline 3 (CíxIc) & 18 & 72,00 & 2 & 8,00 & 5 & 20,00 & 0 & 0,00 & 25 & 100 \\
\hline $1 \quad$ (I59) & 19 & 63,33 & 8 & 26,67 & 3 & 10,00 & 0 & 0,00 & 30 & 100 \\
\hline 13 (EtxCí) & 18 & 60,00 & 2 & 6,67 & 10 & 33,33 & 0 & 0,00 & 30 & 100 \\
\hline 4 (VsxHT) & 14 & 48,27 & 2 & 6,89 & 10 & 34,48 & 3 & 10,34 & 29 & 100 \\
\hline 12 (EtxCí) & 12 & 44,44 & 5 & 18,52 & 5 & 18,52 & 5 & 18,52 & 27 & 100 \\
\hline 9 (CtxHT) & 7 & 26,92 & 7 & 26,92 & 6 & 23,08 & 6 & 23,08 & 26 & 100 \\
\hline $8 \quad(\mathrm{CtxHT})$ & 7 & 31,82 & 3 & 13,64 & 3 & 13,64 & 9 & 40,91 & 22 & 100 \\
\hline $6 \quad(\mathrm{CtxHT})$ & 4 & 15,38 & 2 & 7,69 & 10 & 38,46 & 10 & 38,46 & 26 & 100 \\
\hline $10(\mathrm{CtxHT})$ & 5 & 18,52 & 1 & 3,70 & 7 & 25,93 & 14 & 51,85 & 27 & 100 \\
\hline $5 \quad\left(\operatorname{Ctx} C 1_{2,3}\right)$ & 4 & 17,39 & 0 & 0,00 & 7 & 30,43 & 12 & 52,17 & 23 & 100 \\
\hline 2 (C1́81) & 0 & 0 & 1 & 4,35 & 14 & 60,87 & 8 & 34,78 & 23 & 100 \\
\hline 11 (CtxHT) & 4 & 13,79 & 1 & 3,45 & 4 & 13,79 & 20 & 68,96 & 29 & 100 \\
\hline
\end{tabular}

( $\left.{ }^{1}\right)$ Quantidade de plantas.

Com relação ao vigor vegetativo $(\mathrm{V})$, pelo teste de médias não houve diferença significativa entre os tratamentos 7 (CíxIc) e 3 (CíxIc), sendo esses diferentes dos demais, inclusive das testemunhas (Tabela 4). Vigor vegetativo alto é importante característica como adaptação às geadas, solos pobres, calor e seca (SERA et al., 2002).

Pelo teste de médias não houve diferença significativa para potencial de produção entre os tratamentos (Tabela 4).
Uma das formas de aumentar a produtividade é fazer seleção de progênies para tamanho de grãos. Pelo teste de médias (Tabela 4), verificou-se superioridade dos tratamentos 1 (I59), 4 (VsxHT), 9 (CtxHT) e 5 (CtxCí 2,3), para essa característica, os quais não diferem entre si.

Nos demais tratamentos, notou-se tamanho de grãos estatisticamente iguais à testemunha 2 (Cí81), exceto o 12 (EtxCí), com menor tamanho de grãos. 
É de interesse a utilização de cultivares, com épocas de maturação diferenciadas na propriedade, para escalonar a colheita, proporcionando diminuição do custo (SERA et al., 2002). Deve-se escolher cultivares com épocas de maturação tardias, em regiões de temperaturas elevadas, e cultivares precoces, em regiões frias, pois reduzem os efeitos de temperaturas altas que provocam problemas na formação de grãos e minimizam-se os danos provocados pelas geadas nos frutos verdes (SERA et al., 2002).

A grande variabilidade detectada para maturação dos frutos, evidenciada pelo teste de médias (Tabela 4) e pelo elevado valor do coeficiente de determinação genotípico (Tabela 3), indica boas possibilidades de ganhos com a seleção, tanto para precocidade quanto para maturação tardia. Os tratamentos 12 (EtxCí), 8 (CtxHT), 13 (EtxCí), 9 (CtxHT) e 6 (CtxHT) são constituídos de progênies mais precoces que a 'IAPAR 59' (1(I59)), portanto, valiosas para o desenvolvimento de cultivares com diferentes épocas de maturação, visando ao escalonamento da colheita em regiões mais frias. A progênie 13 (EtxCí) é resistente à mancha aureolada, de maturação precoce, com bom vigor vegetativo, potencial de produção médio, tamanho dos grãos semelhante à 'IAPAR 59' (1(I59)), embora varie quanto à ferrugem alaranjada (Tabela 4). A seleção genealógica em gerações subseqüentes poderá aumentar sua produtividade e resistência à ferrugem alaranjada. Os tratamentos 4 (VsxHT) e 10 (CtxHT), com épocas de maturação estatisticamente iguais à 'Catuaí Vermelho IAC 81' (2(Cí81)), e os tratamentos 7 (CíxIc) e 3 (CíxIc) são as progênies mais tardias.
A progênie 7 (CíxIc) ("Catuaí x Icatú" PRFB 227-1) foi a única com resistência simultânea à mancha aureolada e à ferrugem alaranjada, com $76,92 \%$ e $100 \%$ de plantas resistentes respectivamente, e vigor vegetativo, acima das duas testemunhas do ensaio. $\mathrm{O}$ potencial de produção foi $21,24 \%$ superior, tamanho dos grãos semelhante e época de maturação mais tardia que a da testemunha 'Catuaí Vermelho IAC 81'. A maturação tardia não é desejável, visando a sua utilização em regiões frias, pois, aumenta o risco de danos de geadas sobre os frutos verdes. Selecionouse o tratamento 7 (CíxIc) e as duas melhores plantas de cada repetição. A média das seis plantas, para as características reação à mancha aureolada (MA), reação à ferrugem $(\mathrm{F})$, vigor vegetativo $(\mathrm{V})$, potencial de produção $(\mathrm{P})$, tamanho dos grãos (TG) e época de maturação dos frutos (M) foram 1,00, 1,17, 7,83, 48,71, 3,04 e 2,88 respectivamente. No tratamento 7 (CíxIc), apenas para os caracteres reação à mancha aureolada (MA), vigor vegetativo $(\mathrm{V})$ e potencial de produção $(\mathrm{P})$, houve variabilidade genética dentro e os coeficientes de determinação genotípicos foram, respectivamente, $0,607,0,304$ e 0,307 .

A predição do progresso genético pela seleção do tratamento 7 (CíxIc) indica potencial de ganhos genéticos de $44,58 \%$ e $42,84 \%$, para maior resistência à mancha aureolada e à ferrugem respectivamente (Tabela 6). São ganhos máximos estimados, bastante altos, devido à alta variabilidade genética entre as progênies componentes do experimento. Essa variabilidade pode ter sido observada pela possível presença de algum(s) novo(s) patotipo(s) de P. syringae pv. garcae (KAIRU, 1997), já que as progênies desse experimento haviam sido selecionadas anteriormente para maior resistência.

Tabela 6. Ganho genético esperado entre progênies com a seleção do tratamento 7 (CíxIc), e dentro do tratamento com a seleção de seis plantas (duas em cada repetição)

\begin{tabular}{lrrrrrrr}
\hline \multicolumn{2}{c}{ Entre Progênies } & \multicolumn{2}{c}{ Dentro da Progênie } \\
\hline Características & GS & GS & GS & GS & M.O. & M.M. & GS Total \\
\hline & & $\%$ & & $\%$ & & & $\%$ \\
MA & $-0,8104$ & $-33,91$ & $-0,255$ & $-10,67$ & 2,39 & 1,32 & $-44,58$ \\
F & $-0,9296$ & $-42,84$ & 0,000 & 0,00 & 2,17 & 1,24 & $-42,84$ \\
V & 0,6152 & 9,06 & 0,082 & 1,21 & 6,79 & 7,49 & 10,27 \\
P & 1,3748 & 3,97 & 3,350 & 9,67 & 34,65 & 39,37 & 13,64 \\
TG & $-0,0238$ & $-0,77$ & 0,000 & 0,00 & 3,10 & 3,08 & $-0,77$ \\
M & $-0,6673$ & $-18,23$ & 0,000 & 0,00 & 3,66 & 2,99 & $-18,31$ \\
\hline
\end{tabular}

MA: reação à mancha aureolada. F: reação à ferrugem. V: vigor vegetativo. P: potencial de produção em sacas beneficiadas/ha). TG: tamanho dos grãos. M: época de maturação dos frutos.

GS: Ganho genético esperado com a seleção. M.O.: Média original do ensaio. M.M.: Média melhorada esperada para a próxima geração. 
Alternativamente, a seleção anteriormente realizada em condições de campo, pode não ter ocorrido com a eficiência esperada. Com a seleção das plantas dentro do tratamento estimou-se ganho genético para resistência à mancha aureolada de $10,67 \%$ e não houve variabilidade dentro da progênie para resistência à ferrugem, sendo todas, altamente resistentes a resistentes. As médias melhoradas esperadas na próxima geração são 1,32 e 1,24 para resistência à mancha aureolada e à ferrugem respectivamente.

Para o vigor vegetativo, obteve-se um ganho estimado total de $10,27 \%$, sendo $9,06 \%$ entre progênies e apenas 1,21\% dentro, devido à homogeneidade das plantas. O aumento de $10 \%$ no vigor vegetativo pode significar menor perda em produtividade, no caso de seca, ou a necessidade de podas mais leves, no caso de geadas.

A seleção do tratamento 7 (CíxIc) proporcionaria, para potencial de produção, um ganho genético estimado total de $13,64 \%$, sendo 3,97\% entre as progênies e $9,67 \%$ dentro da progênie. Para o tamanho dos grãos, a seleção não proporcionaria ganho genético esperado relevante. A seleção, para maturação dos frutos, proporcionaria ganho genético esperado de $18,31 \%$ no sentido de mais tardia, esperado, já que o tratamento 7 (CíxIc) foi a progênie mais tardia do experimento.

As seis plantas selecionadas (seis linhagens F6) da progênie 7 (CíxIc) ("Catuaí x Icatú" PRFB 2-271) vão compor os ensaios regionais e as unidades de observação como cultivar experimental, com sementes misturadas, para validação por agricultores. Ao mesmo tempo, as seis linhagens serão instaladas individualmente em campos de semente genética e em um experimento de avanço de geração, onde estarão na geração F6, na Estação Experimental de Londrina, do Instituto Agronômico do Paraná.

\section{CONCLUSÕES}

1. Os resultados sugerem investigar a possibilidade da ocorrência de novo(s) patotipo(s) de P. syringae pv. garcae no Paraná.

2. Observa-se na cultivar 'IAPAR 59' resistência suficiente para reduzir danos causados por P. syringae pv. garcae, causador da mancha aureolada, em regiões de alta ocorrência do patógeno, no Paraná.

3. Na progênie "Catuaí" x "Icatú" PRFB 2-271/F5 (IAPAR 96095), verifica-se resistência simultânea à ferrugem alaranjada e à mancha aureolada e deverá ser testada em ensaios regionais.

\section{AGRADECIMENTOS}

À equipe de Melhoramento Genético de Café do Instituto Agronômico do Paraná (IAPAR) por propiciarem o desenvolvimento dos trabalhos; ao Consórcio Brasileiro de Pesquisa e Desenvolvimento do Café e a Coordenação de Aperfeiçoamento de Pessoal de Nível Superior (CAPES) pelo apoio financeiro, e ao Programa de Doutorado em Fitotecnia da Universidade Estadual de Londrina.

\section{REFERÊNCIAS}

CARDOSO, R.M.L.; SERA, T. Obtenção de cultivares de Coffea arabica L. com resistência simultânea a Hemileia vastatrix Berk. \& Br. e Pseudomonas syringae pv garcae Amaral et al. no Estado do Paraná. In: SIMPÓSIO SOBRE FERRUGENS DO CAFEEIRO, 1983. Oeiras. Resumos... Lisboa, CIFC/IICT, 1984, p. 417-419.

FAZUOLI, L. C. Metodologias, critérios e resultados da seleção em progênies do café Icatu com resistência a Hemileia vastatrix. 1991. 322 f. Tese (Doutorado) UNICAMP, Campinas.

KAIRU, G.M. Biochemical and pathogenic differences bettween Kenyan and Brazilian isolates of Psedomonas syringae pv garcae. Plant Pathology, v. 46, n.2, p.239-246; 1997.

MOHAN, S.K.; CARDOSO, R.M.L.; PAIVA, M.A. Resistência em germoplasma de Coffea ao crestamento bacteriano incitado por Pseudomonas garcae Amaral et al.. Pesquisa Agropecuária Brasileira, Brasília, v.13, n.1, p. 53-64, 1978.

MOHAN, S.K. Investigações sobre Pseudomonas garcae Amaral et al. em cafeeiros. In: CONGRESSO BRASILEIRO DE PESQUISAS CAFEEIRAS, 4., 1976, Caxambu (MG). Resumos... Rio de Janeiro: IBC, 1976. p.56.

MORAES, S.A.; SUGIMORE, M.H.; TOMAZELLO-FILHO, M.; CARVALHO, P. C. T. Resistência de cafeeiros à Pseudomonas garcae In: CONGRESSO BRASILEIRO DE PESQUISAS CAFEEIRAS, 2., 1974, Poços de Caldas (MG). Resumos...Rio de Janeiro; IBC, 1974. p. 183.

PARADELA-FILHO, O.; PARADELA, A.L.; THOMAZIELLO, R.A.; RIBEIRO, I.J.A.; SUGIMORI, M.H.; FAZUOLI, L.C. O complexo Colletotrichum do cafeeiro. Campinas: Instituto Agronômico, 2001. 11p. (Série Tecnológica APTA, Boletim técnico IAC, 191)

PETEK, M.R.;SERA, T.; ALTEIA, M.Z.; TRILLER, C.; AZEVEDO, J.A.; COLOMBO, L.A.; MATA, J.S.; SERA, G.H.; FADELLI, S. Resistência à bacteriose (Pseudomonas syringae pv garcae) derivado do cruzamento entre 'IAPAR 59' e Coffea arabica Sh1 $x$ 'CATUAÍ'. In: SIMPÓSIO DE RECURSOS GENÉTICOS PARA AMÉRICA LATINA E CARIBE, 3., 2001, Londrina. Anais... Londrina: IAPAR, 2001. p.133-134. 
SERA, T. Coffee genetic breeding at IAPAR. Crop Breeding and Applied Biotechnology, v.1, n.2, p. 179-190, 2001.

SERA, T.; ALTEIA, M. Z.; PETEK, M.R. Melhoramento do cafeeiro: variedades melhoradas no Instituto Agronômico do Paraná (IAPAR). In: ZAMBOLIM, L (Ed.). O estado da arte de tecnologias na produção de café. Viçosa: UFV, 2002. p.217-251.
VÁRZEA, V.M.P.; RODRIGUES JR, C.J.; SILVA, M.C.M.L.; GOUVEIA, M.; MARQUES, D.V.; GUERRA-GUIMARÃES, L.; RIBEIRO, A. In: ZAMBOLIM, L. (Ed.). O estado da arte de tecnologias na produção de café. Viçosa: UFV, 2002. p.297-320. 